\title{
PENERAPAN STRATEGI FUNDRAISING DI RUMAH SINGGAH BINA ANAK PERTIWI, JAKARTA
}

\author{
Oleh: \\ Yessi Rachmasari, Soni Akhmad Nulhaqim \& Nurliana Cipta Apsari \\ E-mail: \\ yessirachma19@gmail.com; soninulhaqim@yahoo.com; nurliana.apsari@gmail.com
}

\begin{abstract}
ABSTRAK,
Potret kehidupan anak jalanan yang terjadi saat ini merupakan fenomena yang sering dijumpai di tengah-tengah kehidupan masyarakat, maka perlunya dilakukan pembinaan anak jalanan untuk mengurangi persebaran anak jalanan. Sehingga, rumah singgah menjadi salah satu alternatif kebutuhan terhadap pembinaan anak jalanan. Sebagai organisasi pelayanan sosial, rumah singgah juga memerlukan dana untuk dapat menjalankan setiap program-program pembinaan anak jalanan yang selama ini telah dikelola. Fundraising diperlukan dalam kegiatan pencarian sumber-sumber dana baik melalui donatur maupun dari sumber-sumber lain yang memiliki potensi dalam mengembangkan sebuah organisasi pelayanan sosial, dalam hal ini rumah singgah. Penelitian ini menggunakan metode kualitatif karena dalam penelitian ini ingin mengetahui bagaimana penerapan strategi fundraising yang dilakukan oeh rumah singgah Bina Anak Pertiwi. Studi ini menunjukkan bahwa rumah singgah ini menggunakan strategi fundraising dalam melakukan pembinaan terhadap anak jalanan serta menjalankan setiap programnya. Tiga strategi fundraising yang digunakan yaitu; Acquisition Strategies, Retension Strategies, dan Upgrading strategies.
\end{abstract}

Kata kunci : anak jalanan, rumah singgah, fundraising

\begin{abstract}
Portrait of the life of street children is happening today is a phenomenon that is often encountered in the midst of people's lives, then the need for the development of street children to reduce the spread of street children. Thus, the shelter became one of alternative development needs to street children. As social service organizations, shelters also need funds to be able to run any coaching programs for street children who have been administered. Fundraising is necessary in order to launch the sources of funding through donors or from other sources which have the potential to develop a social service organization, in this case the halfway house. This study uses a qualitative method because in this study wanted to know how the application of a fundraising strategy conducted by the NII shelters Bina Anak Pertiwi. This study shows that the shelter is using fundraising strategy to guide the child in the street and run any program. Three fundraising strategies used are; Acquisition Strategies, Retension Strategies, and upgrading strategies.
\end{abstract}

Keywords: street children, shelter, fundraising 
Potret kehidupan anak jalanan yang terjadi saat ini merupakan fenomena yang sering dijumpai di tengah-tengah kehidupan masyarakat, tak terkecuali di DKI Jakarta. Anak jalanan sering dijumpai di sekitaran lampu merah, kolong jembatan maupun tempatumum dan lainnya. Biasanya untuk mendapatkan uang serta mempertahankan kehidupannya anak jalanan pun bekerja sebagai pengamen, pengemis, pemulung dan sebagainya. Tak jarang pula, kehidupan keras di jalanan membuat anakanak jalanan melakukan perbuatan yang menyimpang, seperti; menjadi pekerja seks, melakukan tindakan kekerasan, bahkan memakai obat-obatan terlarang. Hal itu disebabkan karena keterbatasan keadaan ekonomi maupun kurangnya perhatian dan kasih sayang dari orangtua. Keadaan seperti itulah yang dapat menganggu pertumbuhan dan perkembangan anak jalanan. Seperti yang diungkapkan oleh Soedijar (1998), definisi anak jalanan itu sendiri adalah :

"Anak jalanan itu berusia di antara tujuh hingga lima belas tahun yang mana mereka memilih untuk mencari penghasilan di jalanan, yang tidak jarang menimbulkan konflik ketenangan, ketentraman dan kenyamanan orang lain di sekitarnya, serta tidak jarang membahayakan dirinya sendiri”

Peran serta dari berbagai pihak sntuk melakukan upaya pembinaan terhadap anak jalanan sangat dibutuhkan agar anak-anak jalanan tidak lagi berkeliaran di jalan dan mendapatkan haknya dengan selayaknya. Dijelaskan pula pada Pasal 9 ayat (1) "UU no 23 tahun 2002 tentang Perlindungan Anak" menyebutkan: "Setiap anak berhak memperoleh pendidikan dan pengajaran dalam rangka pengembangan pribadinya dan tingkat kecerdasannya sesuai dengan minat dan bakatnya"

Oleh karena itu, anak jalanan wajib mendapatkan haknya seperti anak-anak yang lain. Maka perlunya dilakukan pembinaan anak jalanan melalui keberadaan rumah singgah. Rumah singgah dapat menjadi salah satu upaya juga dalam mengurangi persebaran anak jalanan di ibukota. Menurut definisi dari Kementerian Sosial, rumah singgah adalah tempat penampungan sementara anak jalanan sebagai wahana pelayanan kesejahteraan sosial (kemsos.go.id).

Rumah singgah merupakan salah satu organisasi pelayanan sosial yang menjadi kebutuhan pada saat ini dalam melakukan pembinaan terhadap anak jalanan. Di DKI Jakarta seperti yang diungkapkan oleh Agusman, Ketua Forum Komunikasi Pengelola Rumah Singgah se-DKI Jakarta pada tahun 2013, Jakarta memiliki 27 rumah singgah yang berada di bawah pengawasan Dinas Sosial. Dengan rincian, sebagai berikut:

Tabel 1.1

Jumlah Rumah Singgah di DKI Jakarta

\begin{tabular}{|c|c|}
\hline Lokasi & $\begin{array}{c}\text { Jumlah Rumah } \\
\text { Singgah }\end{array}$ \\
\hline Jakarta Timur & 7 \\
\hline Jakarta Utara & 5 \\
\hline Jakarta Pusat & 5 \\
\hline Jakarta Selatan & 4 \\
\hline Jakarta Barat & 6 \\
\hline Jumlah & 27 \\
\hline
\end{tabular}

Sumber: Forum Komunikasi Pengelola Rumah Singgah Se-DKI Jakarta

Berkaitan dengan fungsi rumah singgah sebagai tempat pembinaan anak jalanan, maka keberadaan rumah singgah ini dapat memberikan kontribusi bagi kebutuhan masyarakat. Tentu saja, dalam menjalankan aktivitasnya rumah singgah sebagai organisasi pelayanan sosial perlu didukung dengan manajemen pelayanan sosial yang baik. Kettner (2002) mengemukakan lima aspek manajemen dalam organisasi pelayanan sosial, antara lain yaitu: Planning, Organizing, 
Budgeting, Human Resources Development, dan Sistem Informasi. Kelima aspek tersebut berfungsi untuk menunjang kinerja dari program-program organisasi pelayanan sosial dalam mencapai tujuan sebuah organisasi. Salah satu aspek manajemen yang mendukung sebagai kontrol untuk mencapai sebuah tujuan organisasi pelayanan sosial yaitu aspek budgeting. Gates (1980) mengemukakan bahwa dengan adanya budgeting dapat mewujudkan sebuah rencana, program, dan sebagai kontrol untuk meningkatkan efisiensi dan efektifitas dalam organisasi pelayanan sosial.

Sebagai organisasi pelayanan sosial, rumah singgah juga membutuhkan dana untuk menunjang keberlangsungan kegiatannya dalam melakukan pembinaan terhadap anak jalanan. Berdasarkan permasalahan mengenai rumah singgah yang ada pada saat ini, menurut penuturan Raden Harry Hikmat selaku Direktur Pelayanan Sosial Anak Kementerian Sosial mengatakan, bahwa sekitar 60 persen rumah singgah bagi anak jalanan tidak aktif lagi karena dukungan pemerintah terhadap penyelenggaraan fasilitas pelayanan sosial itu melemah dalam beberapa tahun terakhir. Tak hanya hal itu saja, problematika lain yang dihadapi oleh rumah singgah, yaitu penurunan aktivitas rumah singgah yang disebabkan karena berkurangnya dukungan pendanaan dari pemerintah dan lembaga donor. Fakta tersebut merupakan salah satu faktor penyebab yang menjadi hambatan dalam pembinaan anak jalanan. Meskipun demikian, rumah singgah saat ini tidak bisa hanya mengandalkan subsidi dari pemerintah saja karena banyaknya kebutuhan untuk menjalankan setiap aktivitasnya agar mampu bertahan dan berkembang dalam mencapai tujuannya. Sehingga, dibutuhkan upaya untuk mendanai berbagai aktivitas yang dijalankan oleh rumah singgah melalui fundraising dan bantuan dari lembaga donor lain. Fundraising menurut Norton (1998) adalah segala sesuatu yang berkaitan dengan menjual ide kepada orang lain (donor) yang dapat mewujudkan ide tersebut dengan memberikan bantuan berupa uang, sponsor, atau bentuk lain yang dibutuhkan.

Berdasarkan permasalahan tersebut, maka peneliti akan mengkaji bagaimana strategi fundraising di Yayasan Bina Anak Pertiwi berjalan dan berkelanjutan dalam menjalankan aktivitas dalam pembinaan anak jalanan.

\section{PEMBAHASAN}

Fundraising diperlukan dalam kegiatan pencarian sumber-sumber dana, baik melalui donatur maupun dari sumber lainnyaang memiliki potensi dalam mengembangkan sebuah organisasi pelayanan sosial. Selain itu, kegiatan fundraising juga dapat mendukung pengoperasian roda kehidupan maupun pengelolaan keuangan sebuah organisasi. Alasan lain dilakukannya fundraising, yaitu untuk mengurangi ketergantungan sebuah organisasi terhadap lembaga donor utama. Menurut Said, Abidin dan Faizah (2003 : 34) ada tiga cara yang dapat ditempuh oleh organisasi pelayanan sosial dalam menggalang dukungan dari masyarakat.yaitu;

1. Menggalang dana dari sumber yang tersedia, baik dari perorangan, perusahaan, ataupun pemerintah. Untuk menggalangnya, mereka bisa menggunakan beberapa strategi. Yaitu; direct mail, media campaign. Keanggotaan, special event, endowment, dan sebagainya

2. Menciptakan sumber dana baru. Upaya itu dilakukan dengan cara membangun unitunit usaha dan ekonomi yang mampu menghasilkan pendapatan lembaga (earned income)

3. Mengkapitalisasi sumber daya nonfinancial. Disini, lembaga bisa menciptakan dana dari sumber nonfinancial.

Fundraising diperlukan dalam kegiatan pencarian sumber-sumber dana baik melalui 
donatur maupun dari sumber-sumber lain yang memiliki potensi dalam mengembangkan sebuah organisasi pelayanan sosial. Dalam kegiatannya, fundraising memiliki lima tujuan pokok menurut (Juwaini:2005) yaitu:

\section{a. Menghimpun dana}

Menghimpun dana adalah tujuan fundraising yang paling dasar. Termasuk dalam pengertian dana adalah barang atau jasa yang memiliki nilai material. Tujuan inilahyang paling pertama dan utama. Inilah sebab awal mengapa fundraising itu dilakukan. Bahkan kita bisa mengatakan bahwa fundraising yang tidak menghasilkan dana adalah fundraising yang gagal, meskipun memiliki bentuk keberhasilan lainnya. Karena pada akhirnya apabila fundraising tidak menghasilkan dana maka tidak ada sumber daya dihasilkan. Apabila sumber daya sudah tidak ada, maka lembaga akan kehilangan kemampuan untuk terus menjaga kelangsungannya, sehingga pada akhirnya akan mati.

\section{b. Menghimpun donatur}

Tujuan kedua fundraising adalah menghimpun donatur. Lembaga yang melakukan fundraising harus terus menambah jumlah donaturnya. Untuk dapat menambah jumlah donasi, maka ada dua cara yang dapat ditempuh, yaitu menambah donasi dari setiap donatur atau menambah jumlah donatur pada saat setiap donatur mendonasikan dana yang tetap sama. Di antara kedua pilihan tersebut, maka menambah donatur adalah cara yang relatif lebih mudah dari pada menaikkan jumlah donasi dari setiap donatur. Dengan alasan ini maka mau tidak mau fundraising dari waktu ke waktu juga harus berorientasi untuk terus menambah jumlah donatur.

\section{c. Menghimpun simpatisan dan pendukung}

Kadang-kadang ada seseorang atau sekelompok orang yang telah berinteraksi dengan aktivitas fundraising, mereka kemudian terkesan, menilai positif dan bersimpati. Akan tetapi pada saat itu mereka tidak memiliki kemampuan untuk memberikan sesuatu (misal: dana) sebagai donasi karena ketidak mampuan mereka. Kelompok seperti ini kemudian menjadi simpatisan dan pendukung lembaga meskipun tidak menjadi donatur. Kelompok seperti ini akan berusaha mendukung lembaga dan umumnya secara natural bersedia menjadi promotor atau informan positif tentang lembaga kepada orang lain. Kelompok seperti ini juga diperlukan oleh lembaga sebagai pemberi kabar informal kepada setiap orang yang memerlukan.Dengan adanya kelompok simpatisan dan pendukung ini, maka kita memiliki jaringan informasi informal yang sangat menguntungkan.

\section{d. Membangun Citra lembaga}

Disadari atau tidak, aktivitas fundraising yang dilakukan oleh sebuah LSM, baik langsung maupun tidak langsung akan membentuk citra lembaga. Fundraising adalah garda terdepan yang menyampaikan informasi dan berinteraksi dengan masyarakat. Hasil informasi dan interaksi ini akan membentuk citra lembaga dalam benak khalayak. Citra ini bisa bersifat positif, bisa pula bersifat negatif. Dengan citra ini setiap orang akan mempersepsi lembaga, dan ujungnya adalah bersikap atau menunjukkan perilaku terhadap lembaga. Jika citra lembaga positif, maka mereka akan mendukung, bersimpati dan akhirnya memberikan donasi. Sebaliknya kalau citranya negatif, maka mereka akan menghindari, antipati dan mencegah orang untuk melakukan donasi.

\section{e. Memuaskan donatur}

Tujuan kelima dari fundraising adalah memuaskan donatur. Tujuan ini adalah tujuan yang tertinggi. Tujuan memuaskan donatur adalah tujuan yang bernilai jangka panjang, meskipun kegiatannya secara teknis dilakukan sehari-hari. Mengapa memuaskan donatur itu penting? Karena jika donatur puas, maka mereka akan mengulang lagi mendonasikan dananya kepada sebuah lembaga. Juga apabila puas 
mereka akan menceritakan lembaga kepada orang lain secara positif. Secara tidak langsung, donatur yang puas akan menjadi tenaga fundraiser alami (tidak diminta, tidak dilantik dan tidak dibayar). Kebalikannya kalau donatur tidak puas, maka ia akan menghentikan donasi (tidak mengulang lagi) dan menceritakan kepada orang lain tentang lembaga secara negatif. Karena fungsi pekerjaan kegiatan fundraising adalah lebih banyak berinteraksi dengan donatur, maka secara otomatis kegiatan fundraising juga harus bertujuan untuk memuaskan donatur.

Sebagai organisasi pelayanan sosial, rumah singgah juga memerlukan dana untuk dapat menjalankan setiap program-program pembinaan anak jalanan yang selama ini telah dikelola. Yayasan Bina Anak Pertiwi merupakan sebuah yayasan yang menyelenggarakan rumah singgah yang terletak di Jalan Bacang No. 46 Jati Padang, Pasar Minggu, Jakarta Selatan. Yayasan ini didirikan pada tahun 1998 oleh sekelompok mahasiswa karena keprihatiannya terhadap kesejahteraan anak jalanan. Adapun kegiatan yang dilakukan oleh yayasan ini, yaitu menyekolahkan anak-anak jalanan di sekolah umum, pengembangan minat dan bakat, pelatihan keterampilan dan pembinaan untuk membentuk akhlak yang baik. Dalam menjalankan kegiatannya Yayasan Bina Anak Pertiwi tak luput dari strategi fundraising yang dijalankannya selama ini. Dalam melakukan fundraising, Yayasan Bina Anak Pertiwi yang sudah berdiri hampir 17 tahun ini, tidak mudah untuk menjaga keberlangsungan organisasinya hingga sekarang. Yayasan Bina Anak Pertiwi ini juga tidak selalu dapat mengandalkan dana dari pemerintah saja untuk biaya operasional dalam pembinaan anak jalanan. Klein (2006) juga mengatakan bahwa tidak lebih dari 20 persen dari total dana dalam organisasi pelayanan sosial tidak lebih dari pemerintah. Hal ini menunjukkan bahwa Yayasan Bina Anak Pertiwi, yang merupakan organisasi pelayanan sosial, harus mencari sumber dana untuk mendukung keberlansungan organisasinya. Yayasan ini perlu merancang strategi untuk penggalangan dana yang dilakukan dengan bantuan media sosial, internet sebagai media campaign dan menjalin kerja sama dengan perusahaan maupun Lembaga Swadaya Masyarakat (LSM) sebagai bentuk dari strategi fundraising yang dilakukan oleh Yayasan Bina Anak Pertiwi. Yayasan ini juga membuat proposal ke berbagai perusahaan sebagai bentuk pengajuan dari yayasan untuk mencari donatur guna memenuhi kebutuhan dalam pembinaan anak jalanan.

Klein (2006) mengidentifikasi tiga model strategi penggalangan dana sosial, yakni:

\section{Acquisition Strategies}

Tujuan utama strategi ini adalah untuk mendapatkan orang-orang atau para donatur yang belum pernah berdonasi kepada organiasai, seperti halnya; memberikan informsi sebelumnya data melaui website ataupun acara-acara khusus.

\section{Retension Strategies}

Strategi ini berusaha untuk mendapatkan donor untuk memberikan kedua kalinya, ketiga kalinya, dan seterusnya, sampai menjadi terbiasa. pendapatan dari strategi retensi juga digunakan untuk kebutuhan tahunan.

\section{Upgrading Strategies}

Strategi ini bertujuan untuk mendapatkan donor untuk memberikan lebih dari yang mereka berikan sebelumnya . seperti memberikan apresiasi seperti status pendonor tetap yang dapat dilakukan bisa melaui surat, mengkontak secara langsung dan mengundang ke acara khusus.

Jika strategi fundraising dan pemanfaatannya diterapkan dengan tepat dan baik, maka akan dapat menghasilkan dana untuk kebermanfaataan yayasan, seperti; pengembangan yayasan dan pembinaan anak jalanan sesuai dengan tujuan dari Yayasan 
Bina Anak Bangsa. Namun, jika strategi fundraising yang dilakukan Yayasan Bina Anak Pertiwi tidak optimal, maka akan berdampak pada keberlangsungan yayasan dalam menjalankan kegiatannya untuk pembinaan anak jalanan ini.

\section{SIMPULAN}

Yayasan Bina Anak Pertiwi, sebagai payung lembaga dari Rumah Singgah Bina Anak Pertiwi, Pusat Pembinaan Anak dan Pelayanan Kesejahteraan Sosial Masyarakat. Rumah Singgah ini mengembangkan model resource fundraising seperti metode penggalangan dari sumber-sumber konvensional baik secara langsung maupun tidak langsung dan model grant fundraising dengan metode penguatan program pemberdayaan pada keluarga anak jalanan.

Sedangkan dalam mengelola pendayagunaan melalui divisi penyaluran atau pendayagunaan dana dalam program-program yang dilakukan rumah singgah Bina Anak ,adalah: Meningkatkan taraf hidup serta kesejahteraan sosial masyarakat fakir miskin, terutama anak yatim, anak jalanan/terlantar/anak daerah terpencil, serta anak kurang mampu menjadi anak bangsa yang konstruktif dan bermartabat sejalan dengan potensi yang dimilikinya untuk mewujudkan masa depan bangsa yang lebih berkualitas.

Fundraising tidak identik hanya dengan menghimpun dana semata. Ruang lingkupnya begitu luas dan mendalam, pengaruhnya sangat berarti bagi eksistensi dan pertumbuhan sebuah lembaga. Oleh karenanya, tidak begitu mudah untuk memahami ruang lingkup fundraising. Untuk memahaminya terlebih dahulu dibutuhkan pemahaman tentang substansi fundraising tersebut. Substansi fundraising dapat diringas kepada tiga hal yaitu: motivasi, program, dan metode. Adapun yang dimaksud metode atau teknik fundraising, sebagaimana substansi fundraising yang ketiga di atas, adalah suatu bentuk kegiatan yang khas yang dilakukan oleh nādhir dalam rangka menghimpun dana/daya dari masyarakat. Metode ini pada dasarnya dapat dibagi kedua dua jenisyaitlangsung (direct) dan tidak langsung (indirect). Adapun tujuan fundraising ada lima halyaitu: menghimpun danameningkatkan citra, menjalin simpatisan atau pendukung.

Dari konsepsi dan mekanisme kerja fundraising di atas, terlihat bahwa manajemen fundraising pada rumah singgah berkembang dengan produktif dan menghasilkan baik secara finansial maupun non-finansial dalam konteks resource fundraising dan grant fundraising.

Pengembangan program yang dimaksud adalah perluasan penerima manfaat yang tidak hanya terfokus pada masyarakat tidak mampu, tetapi juga memberi kesempatan bagi masyarakat cukup/mampu untuk dapat merasakan dan membuktikan langsung mutu pelayanan dalam pembinaan anak jalanan di rumah singgah Bina Ana Pertiwi. Dalam perspektif manajemen strategis, pengembangan strategi ditekankan pada strategi fokus penerima manfaat atau meminjam. Pembuktian langsung oleh masyarakat tentang mutu pembinaan anak jalanan dengan cara seperti disebut diatas, merupakan strategi tersendiri untuk meningkatkan kepercayaan masyarakat terhadap organisasi penggalang dana. Meningkatnya kepercayaan masyarakat akan berpengaruh positif bagi penerimaan dana untuk pendidikan formal dan non formal, yang itu berarti akan menjamin kualitas dalam pembinaan anak jalanan di rumah singgah. Sebagaimana dijelaskan pada bab sebelumnya, kecukupan dana merupakan salah satu faktor yang mempengaruhi kualitas dalam pembinaan anak jalanan.

Sebenarnya apa yang telah dilakukan oleh Rumah Singgah Bina Anak Pertiwi cukup mendapat simpati masyarakat. Hal itu terbukti dengan penerimaan dana secara umum untuk pembinaan anak jalanan meningkat dari tahun ke tahun. Walaupun demikian, program yang selama ini berjalan perlu dievaluasi dan dikembangkan agar memperoleh kepercayaan 
masyarakat yang lebih luas lagi. Hal ini berhubungan dengan keberlanjutan (sustainbility) lembaga tersebut sebagai organisasi penggalang dana, yang akan berdampak pada penyelenggaraan pelayanan berkualitas.

\section{DAFTAR PUSTAKA}

Klein, Kim. 2011. Fundraising for Social Change $\left(6^{\text {th }}\right.$ edition). San Fransisco: Josey Bass

Norton, Michael. 2002. Menggalang Dana: Penuntun bagi Lembaga Swadaya Masyarakat dan Organisasi Sukarela di Negara-Negara Selatan (Masri Maris, Penerjemah) Jakarta: Yayasan Obor Indonesia

Kettner. 2002. Achieving Excellence in The Management of Human Service
Organizations. Boston: Allyn and Bacon

Hopkins,Bruce, 2009. Starting and Managing A Non Profit Orgnization. Canada: John Willey \& Sons

Ahmad Juwaini.2005. Panduan Direct Mail untuk Fundraising, Jakarta: Piramedia

Arie Kusumastuti Maria Suhardiadi.2003. Hukum Yayasan Indonesia, Jakarta: Abadi

Weiner, Myron.1982.Human Services Management Analisis and Applications. United States of America: They Dorsey Press

Wibawa,Budi, Meilany \& Santoso 2010. Dasar-Dasar Pekerjaan Sosial. Bandung: Widya Padjadjaran

Kesos.unpad.ac.id 